\title{
The Research on the Performance Evaluation of Civil Servant Based on Competency Model
}

\author{
Lei Zhao \\ School of Management, \\ Shanghai University \\ Shanghai, 200444, China \\ E-mail: jolly1949@gmail.com
}

\begin{abstract}
This project roots in some common realistic problems in the performance evaluation of civil servant, such as paying attention to not quality but performance, which has led to serious division of talent development and evaluation in the public sector. So we devote to apply the competency model to job performance evaluation of civil servant.
\end{abstract}

Keywords- Competency; Performance Evaluation; Civil Servant

\section{INTRODUCTION}

In recent years, along with the continuous deepening of public management reform, public sector human resources management has made a series of rapid development, especially in the two key links, personnel assessment and performance evaluation, the technical method and operation system is increasingly perfect.

But the situation that the human resource management department of government still often encounter is: carefully selective graduates from elite school are useless at work; the survivals couldn't prove to be qualified talents although the employment mechanism have become more and more systematic and scientific, and even the strict selection by the examination or interview, which will make serious impact to the optimization management and performance improvement of public sector human resources management undisputed.

Fundamentally, the personnel assessment and performance evaluation has divided seriously in the public sector human resources management, at the same time of their development. The former emphasis the maximization of personnel talent and characteristics, while the latter focus on organizational performance and advocates the contribution to the organization.

The above division has lead to two problems: on the one hand, as an effective performance prediction method, personnel assessment has loosened effectiveness in the public sector human resources management; On the other hand, performance evaluation has become less scientific and objective because of the ignoring personal potential. It has become the important subject in the public sector human resources management that how to combine the potential of talent personnel with the performance evaluation.

\section{FOCUS ON THE INTEGRATION OF PERSONAL ASSESSMENT AND PERFORMANCE EVALUATION IN THE PUBLIC SECTOR}

A. Emphasize Both Quality and Performance Indicator, Which Will Promote the Integration of Evaluation and Assessment in the Public Sector Human Resources Management

The abruption of talent development and performance evaluation in the public sector human resources management embody the under problems in the management practice: In the process of civil servants performance evaluation, what is the true content of the performance? Which is more important exactly: performance or quality?

As we all known, talent is the most precious resource, which is the most significant change due to the modern human resource management idea into public sector management. It is the most fundamental aim for human resource management that develops personal talent as far as possible and provides continuous impetus for the organization's development. Therefore, as the central link of public sector human resources management, performance evaluation should pay attention to the development of personal quality and talent.

So we try to apply the competency model, which is the core technology of talent development, to civil servant performance evaluation, and make the necessary supplement for the existing performance evaluation concept, indicators extraction and results feedback. We pay more attention to not existing performance but the potential competence and talent, which is no doubt conducive to the integration of evaluation and assessment in the public sector human resources management, and realize the truly essence of the modern human resource management.

B. Reasonable Expect and Improve the Performance, and Realize the Optimal Allocation of Organization Human Resources.

The core of human resource management is changing from work to personal talent rapidly, and the personal competence is becoming the key of organizational performance improvement and the source of organizational core competence increasingly [1].

Therefore, in the reform age of public administration, the public sector must actively seek for the effective way to 
improve job performance. The most effective solution is to build the competency model of civil servants, and embed it into the performance evaluation system, which could excavate personal comprehensive quality and talent, and improve personal and organizational performance fundamentally.

Furthermore, as the key technology of talent development and assessment, competency model plays a fundamental and decisive role in human resources management, and certainly will inject new vitality and effect for performance evaluation:

On the one hand, through the competency model, we could find out the key factors and deep reason that affect individual, and build up the truly performance evaluation system laying equal stress on process and result, and improve personal performance fundamentally; On the other hand, performance evaluation based on competency model could truly reflect the personal quality and talent, reasonable expect future job performance, improve performance and adjustment job dialectically, which is beneficial to the optimize configuration of public sector human resource.

\section{THE CURRENT RESEARCH STATUS OF COMPETENCY MODEL}

The concept of competency appeared with the emergence of career. Robert White presented the concept of competence foremost. David McClelland put forward that replace the traditional intelligence test by competence measuring in 1973, and thus is regarded as the Father of the competency modeling method [2].

After that, people made a lot of theoretical and empirical research on the competence, and have got abundant research achievement. While, on the definition of competence, academic circles at home and abroad has not yet unified, which mainly divide two kinds of view: characteristics and behavior.

Boyatzis is a representative scholar of characteristic view. Holding this view, the scholars usually focus on competence, and believe that competence is a kind of potential characteristic, which is causal relational with effective or superior performance in certain job or situation. Characteristic view deems that all individuals characteristic, whether physical or psychological, implicit and explicit, could be defined as competency, as long as it can distinguish outstanding performance from general [3].

Woodruff is a representative scholar of behavior view. Holding this view, the scholars usually focus on competency, and regard it as a kind of behavior expression of performing the job, which is causal relational with excellent performance. They take the above expression, often called behavioral characteristics, as an output (behavior) of individual potential characteristics meeting work standard, and an application or actual behavior of the knowledge, skills, and motives in specific situation [4].

McClelland put forward Competency Iceberg Model in 1973 (Fig.1), which showed the composition and connotation of competence vividly, and is accepted by the academia generally and verified by practice again and again [5].

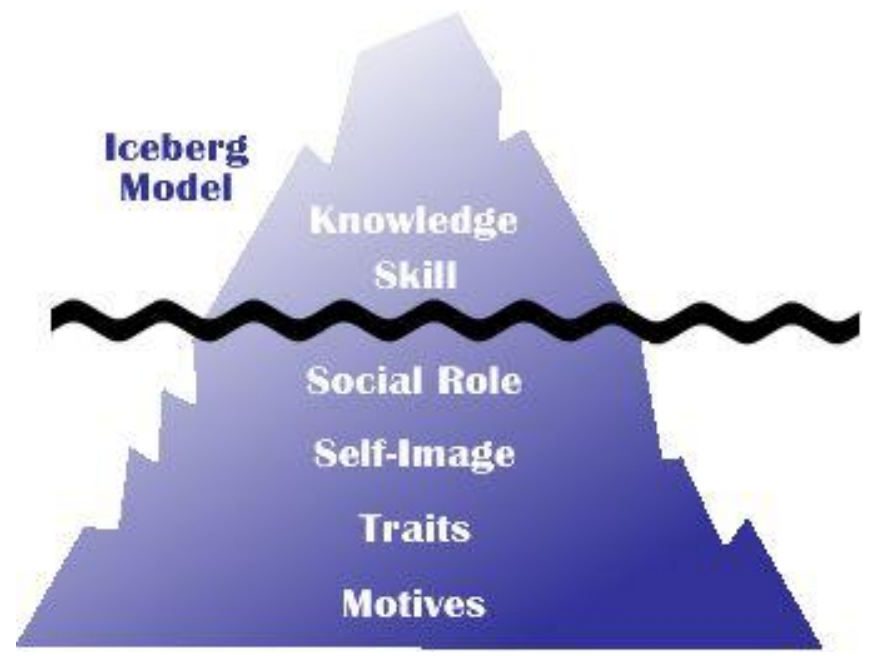

Figure 1. Competency Iceberg Model of McClelland

Competency Iceberg Model considers there are five types of competence: knowledge (skills), social roles, self image, personality, and motivation. Among the above, knowledge (skills), in the visible iceberg above the water, is the most easy to change; social roles, self image, personality, and motivation, hidden below the surface, is more difficult to reach, change or develop.

When the competence on the surface of iceberg is difficult to explain the superior performance of some success, the competence under the surface of iceberg is often the key factor of someone's excellent performance. And that, the deeper competence hides under the surface, the more difficult to be observed and measured, and the more significant impact future performance.

Besides Competency Iceberg Model, the Onion Competency Model is another famous theory model (Fig.2). It was proposed by Richard Boyatzis, an American scholar, in his book "The Effective Managers: High Performance Competency Model" [6].

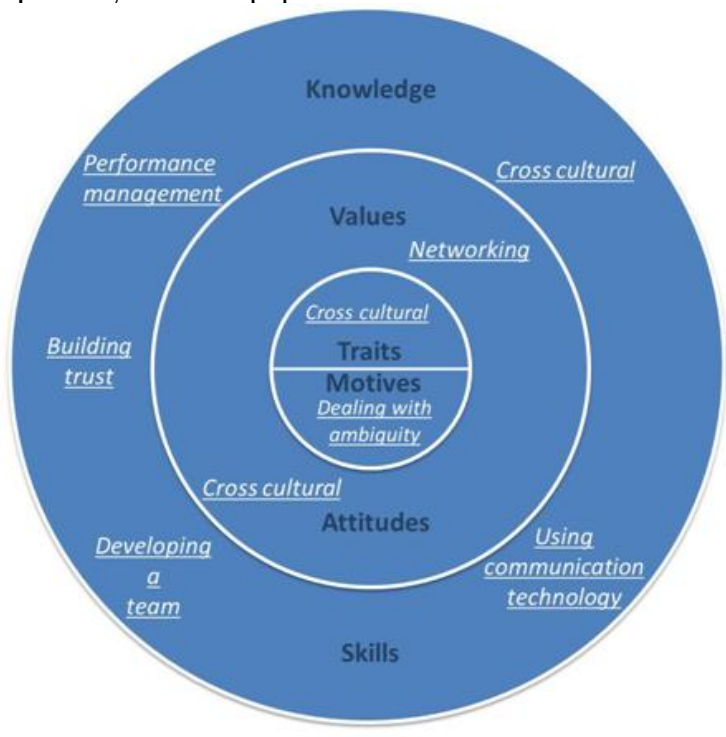

Figure 2. Onion Competency Model of Boyatzis 
In fact, we could regard the Onion Competency Model as another point of view to explain the Competency Iceberg Model. Among all the competence characteristics, from the surface to the centre and layer upon layer, the surface is the basic skills and knowledge, and the inner core is individual potential characteristic.

Whether the Competency Iceberg Model, or the Onion Competency Model, all deem that the potential, implicit, and deep characteristics is the core element to determine the personal behavior and work performance.

\section{THE APPLICATION OF COMPETENCY MODEL TO THE CIVIL SERVANT'S PERFORMANCE EVALUATION}

A. The Application of Competency Characteristic to the Design Concept of Evaluating

The performance evaluation based on competency characteristics pay more attention to personal competency, which is the key factor of performance. It could break the limitation of traditional evaluation method, which emphasizes short-term goals excessively.

In particular, the traditional performance evaluation focus on the indicators which is directly related to the organization strategic goals, such as financial indicators, achievement indicators; and the performance evaluation based on competency pay more attention to the indirectly indicators at the same time, especially the indicators of competence and personal talent (i.e., the potential part of the iceberg below the surface in the model).

In fact, these indicators are the deep foundation and basis of personal knowledge, skills, (dominant part of the iceberg above the surface in the model) and the realization of organization strategic target, although they are difficult to observe and evaluate, and seem to have nothing to do with the organization strategic objectives, not as financial indicators, achievement indicators.

Based on the above analysis, we describe the performance influence factors embedded competency characteristic by the following formula:

$$
\mathrm{p}=\mathrm{f}(\mathrm{c}, \quad \mathrm{o}, \mathrm{e}, \mathrm{m}, \cdots)
$$

Among them, "p" means to performance, "c" means to competency (generally includes the talent such as knowledge, skills, attitudes, etc.), "o" means to opportunity, "e" means to environment, "m" means to motivation [7]. This formula can be displayed through the performance matrix mode of competency and performance (Fig. 4) [8].

B. The Application of Competency Model to the Extraction of Evaluating Indicators

- The design of KPI based on the combination of KBI (key behavior indicators) and KCI (key consequence indicator)

"Performance $=$ right results + right process" [9]. Based on "the right consequence", the traditional performance evaluation assesses KPI through KCI, which attaches great importance to the value contribution of not the process but the consequence.

Another application requirements of the KPI design embedded competency model is to focus on the value contribution of behavior process (rather than behavioral consequence), which is the introduction of KBI.

$\mathrm{KBI}$ refers to the effective behaviors during employees complete their work in some areas. These behaviors would not always influence the short-term performance result obviously and directly, however, whose advantages or disadvantages are sure to impact the long-term performance indirectly and profoundly. If KCI is the quantification of the consequence, the KBI is the quantification of process.

At the same time of performance evaluation, KBI also could predict the performance and value contribution of employee.

- The design of KPI embedded the development indicators of competency

Based on the extraction of the KBI, we can also embed the development indicators of competency in the KPI design according to personal talent, in order to predict individual performance more accurately, which also are the new thought and method for performance evaluation from competency model.

In other words, when we evaluate someone's performance, extract indicators from the three aspects, those are result, process and competency development of work task, which could make the best balance between the individual performance improvement, the organization strategic goals, and personal talent development.

The extraction of KBI and competency development indicators also should follow the SMART principles, namely specific, measurable, attainable, realistic and timebased. The specific standards include five kinds of forms, which are frequency standard (the occurrence frequency of behavior), classification standard (the classification of behavior), order standard (the order of behavior in the whole), gap standard (the gap between behavior and objective), ratio standard (the ratio between behavior and objective), etc. The extraction methods usually adopt such technology as behavior observation, in-depth interview, and questionnaire survey, and so on.

C. The Application of Competency Model to the Result Feedback of Evaluating

The application of competency model to performance evaluation also relates to the results feedback of evaluation. In addition to the traditional feedback function, such as performance improvement, salary incentive, position promotion, etc., the results feedback of evaluation based on competency model pay more attention to scientific prediction of future performance and the rational allocation of organization human resources.

- The scientific prediction of future performance

As mentioned before, the traditional performance evaluation are often concerned with a small part of observable quality on the surface of iceberg model, such as professional knowledge, job skills, etc. But what determines a person's behavior is relatively deep quality most of time, which could not be directly observed, but has the characteristics of stability of sustainability.

Therefore, performance evaluation based on competency model pay more attention to how to predict personal performance scientifically and accurately in the future 
through measuring and unearthing the potential quality and ability of talents.

- The rational allocation and adjustment of organization human resources.

Performance evaluation based on competency model could give more clear expression to personal advantages and potential for the organization and individual through the feedback and communication. Base on the above, organization could be more aware of how to provide resources, conditions and support for the most effective development of employee's potential, such as, what kind of training plan to be offered, what kind of encouraging and management measures to be cooperated, what kind of adjustment on the job, what kind of occupation planning for staff, and so on. Through the above, we could achieve the best match between individual and job, which is the rational allocation of the organization human resources.

\section{ACKNOWLEDGMENT}

Thanks for funding from the Ministry of Education Social Science Youth Fund Project "On Police Performance and Governance Mechanism of Traffic Congestion in Our Big Cities" (project number: 11YJC630295).

\section{REFERENCES}

[1] Daniel Goleman, "Primal leadership: realizing the power of emotional intelligence", Harvard Business School Pr., vol. 16, pp. 2126, 2002.

[2] Jay A, Douglas A, "Ready rethinking leadership competencies", Leader to Leader, vol. 32, pp. 3-9, 2004.

[3] Jane Bozarth, "Training manager competencies", Training, vol. 41, pp. 26-29, 2004.

[4] Jokinen, Tiina, "Global leadership competencies: a review and discussion", Journal of European Industrial Training, vol. 29, pp. 1725, 2005.

[5] McClelland D C., "Testing for competence rather than for intelligence", American Psychologist, vol. 28, pp. 12-21, 1973.

[6] Meevoy Glenn M, Hayton James C, "A competency-based model for development human resource professionals", Journal of Management Education, vol. 29, pp. 33-37, 2005.

[7] Osborne, Carl A, "Professional competency: how committed are you to improvement?", The News Magazine of Veterinary Medicine, vol. 34, pp. 56-62, 2003.

[8] Ramsey V Jean, “A typology of intergroup competencies", Journal of Applied Behavioral Science, vol. 41, pp. 33-38, 2005.

[9] Robert M, Brown Jr, "Correctional leadership competencies for the 21st Century”, Corrections Today,vol. 26, pp. 17-21, 2005.

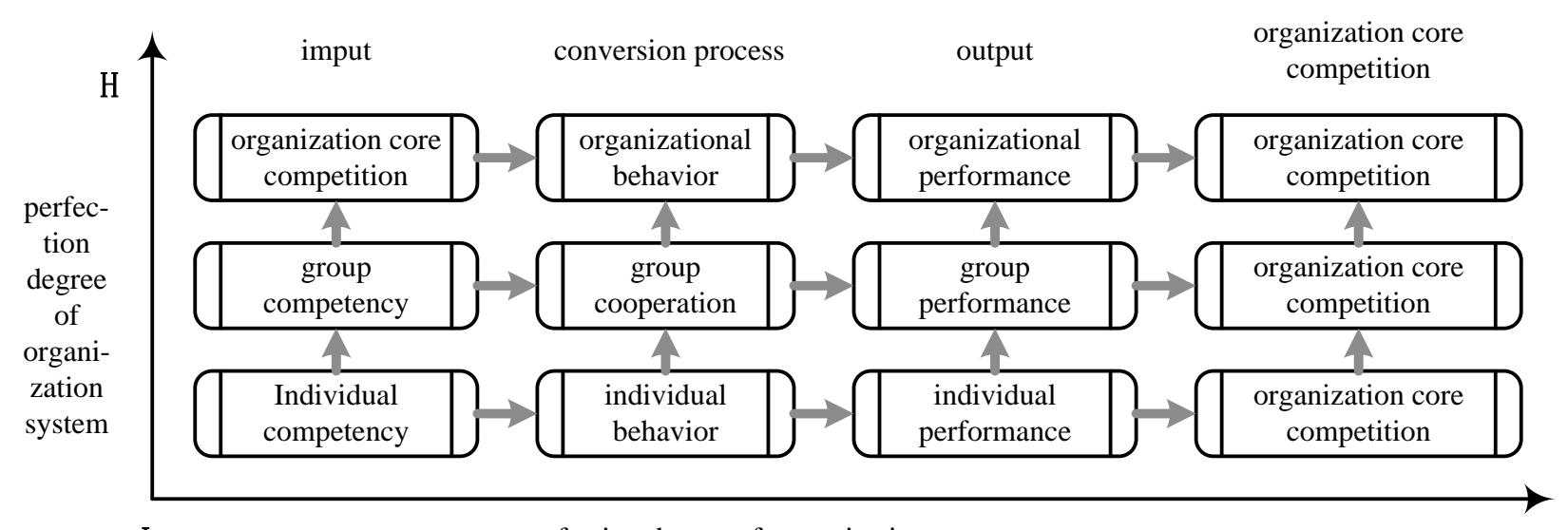

$\mathrm{L}$

perfection degree of organization system

Figure 3. . Matrix Mode of Competency and Performance 